\title{
Stimulation of Glucose Metabolism in Trichophyton mentagrophytes during Incubation in Increased Carbon Dioxide Tension
}

\author{
By B. CHIN AND S. G. KNIGHT \\ Department of Bacteriology, University of Wisconsin, Madison, Wisconsin, U.S.A.
}

(Received 21 May 1962)

\begin{abstract}
SUMMARY
An inducible UDPG pyrophosphorylase (UTP : $\alpha$-D-glucose-1-phosphate uridyltransferase, EC 2.7.7.9) has been demonstrated in cell-free extracts from Trichophyton mentagrophytes incubated in increasing atmospheric tensions of carbon dioxide. Assays of related enzymes have shown that UDPG pyrophosphorylase is not the only enzyme induced by $\mathrm{CO}_{2}$. Glucose-6-phosphate dehydrogenase (EC 1.1.1 .49) and glucose-phosphate isomerase (EC 5.3.1.7) were more strongly stimulated than UDPG pyrophosphorylase. Hexokinase (EC 2.7.1.1), phosphoglucomutase (EC 2.7.5.1) and 6-phosphogluconate dehydrogenase (EC 1.1.1.43) were more weakly stimulated than UDPG pyrophosphorylase. The stimulation of UDPG pyrophosphorylase does not occur as a result of sequential induction.
\end{abstract}

\section{INTRODUCTION}

Two previous papers from this laboratory (Chin \& Knight, 1957, 1963) described the stimulation of macroconidial formation in Trichophyton mentagrophytes when the organism was grown on Sabouraud's glucose medium and incubated under increasing atmospheric tensions of $\mathrm{CO}_{2}$. When glucose was omitted from the medium, macroconidial formation was not stimulated. Macroconidia contain $33 \%$ acidsoluble carbohydrate; microconidia and the whole culture of a strain, which produces microconidia but no macroconidia, contain $11 \%$ and $12 \%$ carbohydrate, respectively. A correlation between increase of acid-soluble carbohydrate and macroconidial formation was demonstrated in whole cultures as they were incubated in increased $\mathrm{CO}_{2}$ tensions. Two strains, 5-7 and 1-2-1, were strongly stimulated to form macroconidia and increase in carbohydrate content; two strains, 1-1-2 and 1-3-1, were weakly stimulated to form macroconidia and did not increase in carbohydrate content.

A preliminary experiment, which forms the basis of this paper, demonstrated the stimulation of uridinediphosphoglucose (UDPG) pyrophosphorylase (UTP: $\alpha$-Dglucose-1-phosphate uridyltransferase, EC 2.7.7.9) activity in cell-free extracts of cultures incubated under increased $\mathrm{CO}_{2}$ tensions. The study of polysaccharide formation during induction of macroconidial formation by incubation of the organism in increased $\mathrm{CO}_{2}$ tensions was divided into three parts : (1) the effect of $\mathrm{CO}_{2}$ on other enzymes involved in polysaccharide formation; (2) the chemical nature of the polysaccharide; (3) an attempt to demonstrate the transfer of glucose from UDPG to polysaccharide. The first part of these studies is described in this paper. 


\section{METHODS}

Mutants and culture methods. The mutants and culture methods used were as previously described (Chin \& Knight, 1957, 1963). Trichophyton mentagrophytes strains 5-7 and 12-1 which are strongly stimulated to form macroconidia and increase in carbohydrate content during incubation in increased $\mathrm{CO}_{2}$ tensions, as well as strains 1-1-2 and 1-3-1 which are weakly stimulated to form macroconidia and do not increase in carbohydrate content, were used in the present work. Cultures were grown as surface mats on Sabouraud's liquid medium under increasing tensions of $\mathrm{CO}_{2}$ (normal air to $16 \%, \mathrm{v} / \mathrm{v}$ ). The inoculating and gassing procedures were as described previously.

Cell-free extracts. After 4 days of incubation at $30^{\circ}$, floating cultures were washed by pouring off the medium and refloating the culture mats with water 4 times. The mycelial mats were transferred to chilled mortars, and after cold $0.02 \mathrm{M}$-sodium acetate buffer ( $\mathrm{pH} \mathrm{5.9)}$ and acid-washed sand were added, the mats were crushed with a chilled pestle for $5 \mathrm{~min}$. The crushed material and sand was transferred to test tubes and the supernatant solutions separated by centrifugation at $700 \mathrm{~g}$ for $5 \mathrm{~min}$. The supernatant solutions, which will be referred to as cell-free extracts, were withdrawn with a pipetting bulb.

Protein determination. The protein content of cell-free extracts was measured by the method of Lowry, Rosenbrough, Farr \& Randall (1951) with bovine serum albumin as the standard.

Assays of enzymes. Enzymatic activities of cell-free extracts were measured in a Beckman Model DK-II Recording Spectrophotometer with a thermostatically controlled $\left(30^{\circ}\right)$ cuvette holder and $1 \mathrm{ml}$. silica cuvettes. All enzymes, with the exception of UDPG pyrophosphorylase, were assayed by taking advantage of an active glucose-6-phosphate dehydrogenase (EC 1.1.1.49) in cell-free extracts and measured by the reduction of nicotinamide-adenine dinucleotide phosphate (NADP) at $340 \mathrm{~m} \mu$. Cell-free extract equivalent to $100 \mu \mathrm{g}$. protein was used in each assay. However, where activities were low, notably in the assay of hexokinase (EC 2.7.1.1), up to $500 \mu \mathrm{g}$. protein was used. Specific activities are expressed as the increase in optical density at $340 \mathrm{~m} \mu / \mathrm{mg}$. protein/min.

Hexokinase (EC 2.7.1.1). The hexokinase assay was adapted from the method of Chattaway, Thompson \& Barlow (1960), using a volume of $1 \mathrm{ml}$. The reaction mixture contained $30 \mu$ moles 2-amino-2-hydroxymethylpropane-1,3-diol (tris)

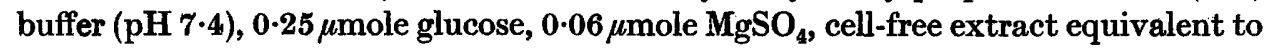
$100 \mu \mathrm{g}$. protein, $0.50 \mu$ mole NADP and $1.00 \mu$ mole adenosine triphosphate (ATP). ATP was omitted from the reference cuvette and added to the sample cuvette to start the reaction.

Glucose-6-phosphate dehydrogenase (EC 1.1.1.49). Glucose-6-phosphate dehydrogenase activity was assayed by an adaptation of the phosphohexoseisomerase assay by Slein (1955). The reaction mixture contained $30 \mu$ moles tris buffer ( $\mathrm{pH} 7 \cdot 4$ ), $0.25 \mu$ mole glucose-6-phosphate, $1.00 \mu$ mole $\mathrm{MgCl}_{2}, 0.50 \mu \mathrm{mole}$ NADP and cell-free extract equivalent to $100 \mu \mathrm{g}$. protein in a total reaction volume of $1 \mathrm{ml}$. Glucose-6phosphate was omitted from the reference cuvette and added to the sample cuvette to start the reaction.

Glucosephosphate isomerase (EC 5.3.1.9). Glucosephosphate isomerase was 
assayed by the method of Slein (1955) in a total reaction volume of $1 \mathrm{ml}$. The reaction mixture contained $30 \mu$ moles tris buffer $(\mathrm{pH} 7 \cdot 4), 0 \cdot 25 \mu$ mole fructose-6-phosphate, $1.00 \mu$ mole $\mathrm{MgCl}_{2}, 0.50 \mu$ mole $\mathrm{NADP}$, and cell-free extract equivalent to $100 \mu \mathrm{g}$. protein. Fructose-6-phosphate was omitted from the reference cuvette and added to the sample cuvette to start the reaction.

6-Phosphogluconate dehydrogenase (EC 1.1.1.43). 6-Phosphogluconate dehydrogenase was assayed after adapting the method of Chattaway et al. (1960) to a reaction volume of $1 \mathrm{ml}$. The reaction mixture contained $30 \mu$ mole tris buffer ( $\mathrm{pH} 7 \cdot 4$ ), $0 \cdot 25 \mu$ mole 6-phosphogluconate, $0.60 \mu$ mole $\mathrm{MnCl}_{2}, 0.50 \mu$ mole $\mathrm{NADP}$, and cell-free extract equivalent to $100 \mu \mathrm{g}$. protein. 6-Phosphogluconate was omitted from the reference cuvette and added to the sample cuvette to start the reaction.

Phosphoglucomutase (EC 2.7.5.1). Phosphoglucomutase was assayed after adapting the method of Chattaway et al. (1960) to a reaction volume of $1 \mathrm{ml}$. The reaction mixture contained $30 \mu$ moles tris buffer (pH 7.4), 0.25 $\mu$ mole glucose-1phosphate, $0.60 \mu$ mole $\mathrm{MnCl}_{2}, 0.50 \mu$ mole NADP, and cell-free extract equivalent to $100 \mu \mathrm{g}$. protein. Glucose-1-phosphate was omitted from the reference cuvette and added to the sample cuvette to start the reaction.

UDPG pyrophosphorylase (EC 2.7.7.9). UDPG pyrophosphorylase was assayed by a modification of the method of Kalckar \& Anderson (1957). The reaction mixture contained, in a volume of $1 \mathrm{ml}$, $100 \mu$ moles glycine buffer ( $\mathrm{pH} \mathrm{8.7)}, 0 \cdot 1 \mu$ mole uridine triphosphate (UTP), $0 \cdot 6 \mu$ mole glucose-1-phosphate (G-1-P), 1.0 $\mu$ mole $\mathrm{MgCl}_{2}, 1 \cdot 0 \mu$ mole NAD, cell-free extract equivalent to $100 \mu \mathrm{g}$. protein, and 5 units commercial UDPG dehydrogenase (Sigma Chemical Co.). Two reactions were run simultaneously: the formation of UDPG from UTP and G-1-P by UDPG pyrophosphorylase and the oxidation-reduction of UDPG to UDP-glucuronic acid and NAD to $\mathrm{NADH}_{2}$ by UDPG dehydrogenase (EC 1.1.1.22). Under the conditions described, UDPG pyrophosphorylase was maintained as the rate-limiting reaction. UTP was omitted from the reference cuvette and added to the sample cuvette to start the reaction. Progress of the reaction was measured by the reduction of NAD at $340 \mathrm{~m} \mu$.

\section{RESULTS AND DISCUSSION}

The demonstration of an inducible UDPG pyrophosphorylase in Trichophyton mentagrophytes during incubation in increasing carbon dioxide tensions is presented as presumptive evidence that the concomitant accumulation of high levels of polysaccharide proceeds via this pathway rather than directly through glucose-1phosphate directly (Sols, 1961). The experiments in this paper were designed to determine whether UDPG pyrophosphorylase was the only enzyme, in the early steps of glucose metabolism, which was stimulated by $\mathrm{CO}_{2}$, or, if other enzymes are stimulated, whether the induction of UDPG pyrophosphorylase is sequential (Stanier, 1950). Four strains of $T$. mentagrophytes, derived from the same parent, were used. Two strains, 5-7 and 1-2-1, responded strongly to incubation in increased $\mathrm{CO}_{2}$ tensions; macroconidial formation was profuse and high levels of polysaccharide accumulated. Two strains, 1-1-2 and 1-3-1, responded weakly to incubation in increased $\mathrm{CO}_{2}$ tensions; macroconidial formation was poor and high levels of polysaccharide were not accumulated. Cell-free extracts from cultures incubated in increasing $\mathrm{CO}_{2}$ tensions were assayed for hexokinase, phosphoglucomutase, UDPG 
pyrophosphorylase, glucose-6-phosphate dehydrogenase, 6-phosphogluconate dehydrogenase, and glucosephosphate isomerase activities. The results of these assays, as they are depicted in Figs. 1, 2, 3 and 4, demonstrate that UDPG pyrophosphorylase was not the only enzyme which was induced by $\mathrm{CO}_{2}$. Glucose-6-phosphate dehydrogenase and glucosephosphate isomerase were more strongly stimulated than UDPG pyrophosphorylase. Hexokinase, phosphoglucomutase and 6-phosphogluconate dehydrogenase were more weakly stimulated, if at all, than UDPG pyrophosphorylase. Sequential induction of UDPG pyrophosphorylase, through stepwise induction of hexokinase and then phosphoglucomutase before induction of UDPG pyrophosphorylase, was not observed.

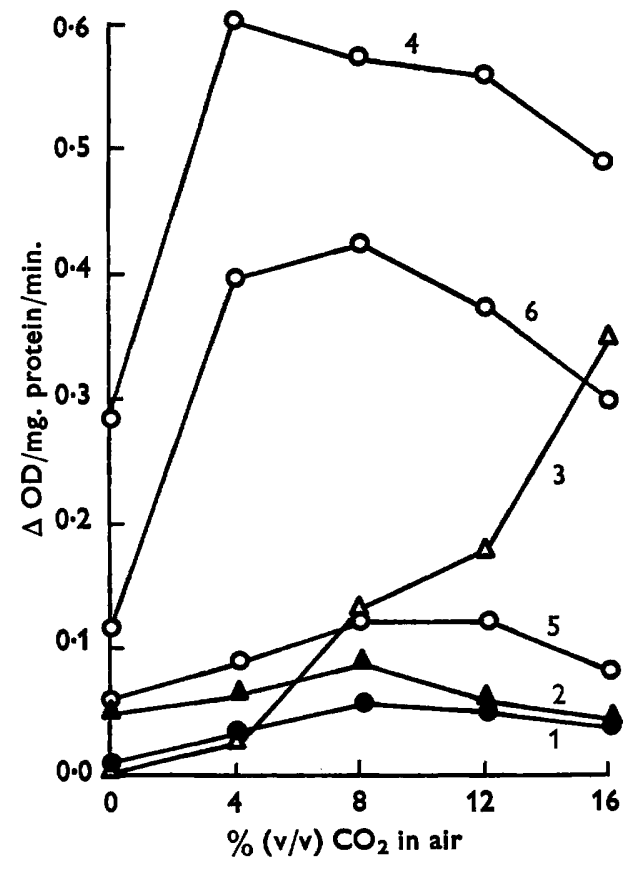

Fig. 1

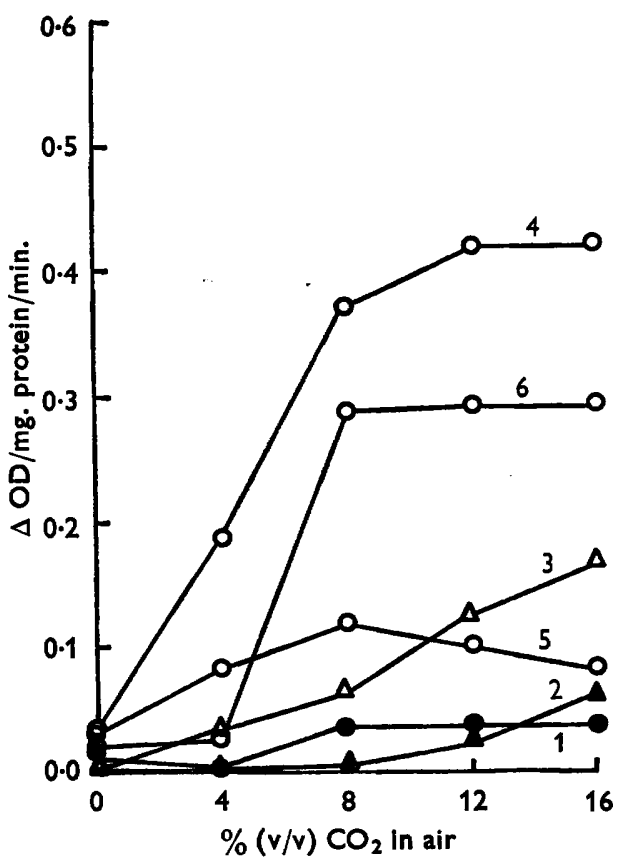

Fig. 2

Fig. 1. Changes in specific activities, as $\Delta O D / \mathrm{mg}$. protein $/ \mathrm{min}$., of enzymes in cell-free extracts from strain 1-2-1 grown in increased carbon dioxide tensions. The enzymes assayed were (1) hexokinase, (2) phosphoglucomutase, (3) UDPG pyrophosphorylase, (4) glucose-6-phosphate dehydrogenase, (5) 6-phosphogluconate dehydrogenase and (6) glucosephosphate isomerase.

Fig. 2. Changes in specific activities, as $\Delta O D / \mathrm{mg}$. protein/min., of enzymes in cell-free extracts from strain 5-7 grown in increased carbon dioxide tensions. The enzymes assayed were (1) hexokinase, (2) phosphoglucomutase, (3) UDPG pyrophosphorylase, (4) glucose6-phosphate dehydrogenase, (5) 6-phosphogluconate dehydrogenase, and (6) glucosephosphate isomerase.

On the other hand, conditions which contribute to the accumulation of polysaccharide during incubation in increased $\mathrm{CO}_{2}$ tensions were shown to exist. The greatest amount of enzyme stimulation resided in glucose-6-phosphate dehydrogenase, glucosephosphate isomerase and UDPG pyrophosphorylase. Figures 1 and 2 show that UDPG pyrophosphorylase activity in strains 5-7 and 1-2-1, which were 
strongly stimulated by $\mathrm{CO}_{2}$ to form macroconidia and accumulate polysaccharide, continued to increase after glucose-6-phosphate dehydrogenase, the first enzyme leading into the hexosemonophosphate shunt, and glucosephosphate isomerase, the first enzyme leading into glycolysis, had attained maximum stimulation. In strain 1-3-1, which was weakly stimulated by $\mathrm{CO}_{2}$ to form macroconidia and accumulate polysaccharide, the stimulation of UDPG pyrophosphorylase activity followed a course similar to those of glucose-6-phosphate dehydrogenase and glucosephosphate isomerase activities. These three enzymes were stimulated (Fig. 3) to their maxima at $8 \%(\mathrm{v} / \mathrm{v}) \mathrm{CO}_{2}$. Figure 4 shows that the stimulation of all enzymes in strain 1-1-2, which responded poorly to $\mathrm{CO}_{2}$, was weaker than in the other strains tested.

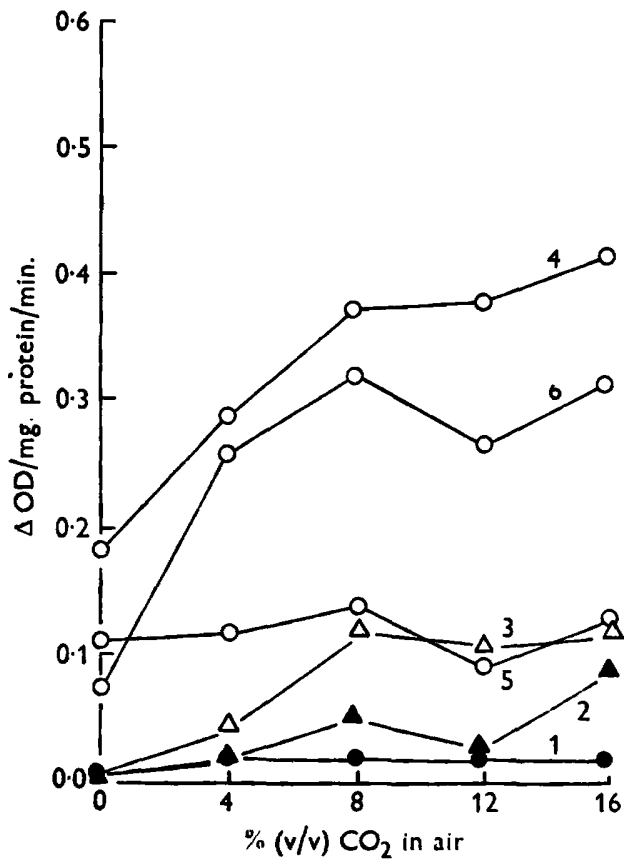

Fig. 3

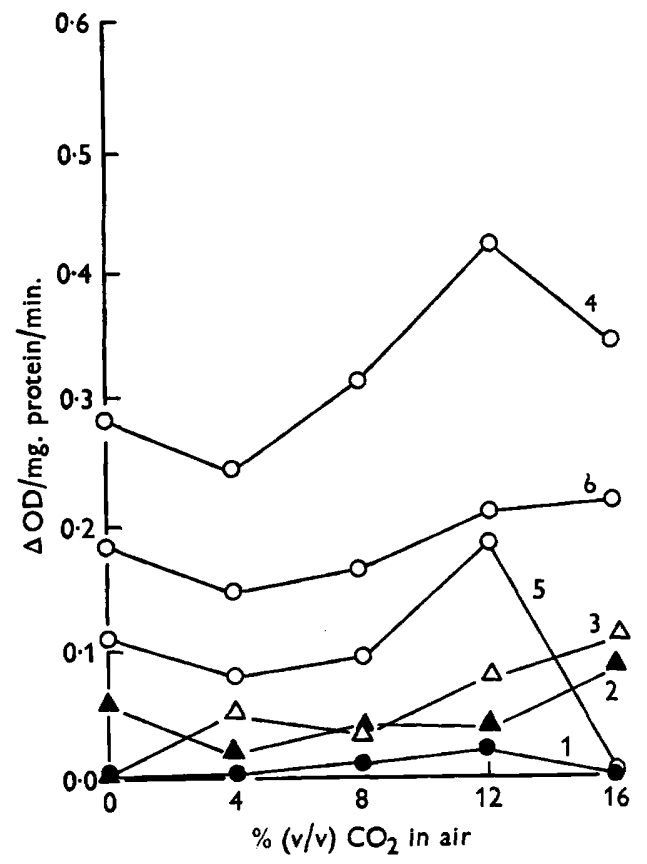

Fig. 4

Fig. 3. Changes in specific activities, as $\Delta O D / \mathrm{mg}$. protein $/ \mathrm{min}$., of enzymes in cell-free extracts from strain 1-3-1 grown in increased carbon dioxide tensions. The enzymes assayed were (1) hexokinase, (2) phosphoglucomutase, (3) UDPG pyrophosphorylase, (4) glucose-6-phosphate dehydrogenase, (5) 6-phosphogluconate dehydrogenase, and (6) glucosephosphate isomerase.

Fig. 4. Changes in specific activities, as $\Delta O D / \mathrm{mg}$. protein $/ \mathrm{min}$, of enzymes in cell-free extracts from strain 1-2-1 grown in increased carbon dioxide tensions. The enzymes assayed were (1) hexokinase, (2) phosphoglucomutase, (3) UDPG pyrophosphorylase, (4) glucose-6-phosphate dehydrogenase, (5) 6-phosphogluconate dehydrogenase and (6) glucosephosphate isomerase.

These results pose two questions which must be answered as the physiological study of Trichophyton mentagrophytes is continued. What is the mechanism by which $\mathrm{CO}_{2}$ induces glucose-6-phosphate dehydrogenase, glucosephosphate isomerase and UDPG pyrophosphorylase? Does the stimulation of glucose-6-phosphate dehydrogenase and glucosephosphate isomerase imply that $\mathrm{CO}_{2}$ may bring about 
macroconidia formation by stimulating the hexosemonophosphate shunt and/or glycolysis?

This work was supported by Grant E-1201 from the National Institutes of Health, U.S.A.

\section{REFERENCES}

Chattaway, F. W., Thompson, C. C. \& Barlow, A. J. E. (1960). Carbohydrate metabolism in Microsporum canis. J. gen. Microbiol. 22, 649.

ChIN, B. \& KNIGHT, S. G. (1957). Growth of Trichophyton mentagrophytes and Trichophyton rubrum in increased carbon dioxide tensions. J. gen. Microbiol. 16, 642.

Chin, B. \& KNIGHT, S. G. (1963). Trichophyton mentagrophytes: Changes in gross chemical components during incubation in increased carbon dioxide tensions. J. gen. Microbiol. 30, 113.

Kalckar, H. M. \& ANDerson, E. P. (1957). Determination of UDPG and UTP by means of UDPG dehydrogenase. II. Enzymatic determination of UTP. In Methods of Enzymo$\log y$, 3, 976. Ed. by S. P. Colowick \& N. O. Kaplan. New York: Academic Press Inc.

Lowry, O. H., Rosenbrough, W. J., Farr, A. L. \& Randall, R. J. (1951). Protein measurements with folin phenol reagent. J. biol. Chem. 193, 265.

Srein, M. W. (1955). Phosphohexoseisomerases in muscle. In Methods of Enzymology, 1, 299. Ed. by S. P. Colowick \& N. O. Kaplan. New York: Academic Press Inc.

Sols, A. (1961). Carbohydrate metabolism. Annu. Rev. Biochem. 30, 213.

Stanier, R. Y. (1950). Problems of bacterial oxidative metabolism. Bact. Rev. 14, 179. 